\title{
MICROBIAL REDUCTION OF THE SIDE-CHAIN CARBONYL OF DAUNORUBICIN AND N-ACETYLDAUNORUBICIN
}

\author{
A. A. Aszalos, N. R. Bachur ${ }^{1}$, B. K. Hamilton, A. F. Langlykke \\ P. P. ROLleR ${ }^{2}$, M. Y. SHeIKH ${ }^{3}$, M. S. SUTPHIN \\ M. C. Thomas, D. A. Wareheim and L. H. Wright \\ Chemotherapy Fermentation Laboratory \\ NCI Frederick Cancer Research Center, P. O. Box B \\ Frederick, Maryland 21701, U.S.A. \\ 1. Laboratory of Clinical Biochemistry, Baltimore Cancer Research Center, Baltimore, \\ MD 21211, U.S.A. \\ 2. Analytical Chemistry Unit, Carcinogen Metabolism and Toxicology Branch, \\ National Cancer Institute, Bethesda, MD 20014, U.S.A. \\ 3. Department of Chemistry, Stanford University, Stanford, CA 94305, U.S.A. \\ 4. Analytical Chemistry Section, Frederick Cancer Research Center, Frederick, MD \\ 21701, U.S.A.
}

(Received for publication August 28, 1976)

\begin{abstract}
Microorganisms reduced the side-chain carbonyl of daunorubicin to yield 13dihydrodaunorubicin (daunorubicinol; daunomycinol). This microbial transformation occurred under aerobic conditions in agitated baffled shake flasks incubated at $37^{\circ} \mathrm{C}$. The microorganisms were first grown in a medium which supported dense growth. Daunorubicin- $\mathrm{HCl}$ was then added. Following a period of incubation, broths were adjusted to $\mathrm{pH} 10.0$ and extracted with chloroform. Daunorubicinol was recovered and purified from the chloroform extracts by preparative TLC. Identity of the daunorubicinol was established by TLC and spectroscopy (UV-Vis, IR, NMR, MS, CD and ORD).

$\mathrm{N}$-Acetyldaunorubicin was likewise reduced microbially to $\mathrm{N}$-acetyldaunorubicinol. $\mathrm{N}$-Acetyldaunorubicinol appears to be a new compound which is yet to be tested for antitumor activity.
\end{abstract}

WILEY and MARSHALL ${ }^{1)}$ have reported in a recent communication to this journal on anaerobic microbial reductive cleavage of several anthracycline antibiotics to yield 7-deoxyanthracycline aglycones. Their work was undertaken because many anthracycline antibiotics exhibit antitumor activities, and microbial transformation is one method with potential for modifying anthracycline structures to produce new agents for antitumor testing. For the same reason, we too have been exploring microbial transformation of anthracycline antibiotics. During the course of our studies, we have observed under aerobic conditions the microbial reduction of the side-chain carbonyl of daunorubicin to yield 13-dihydrodaunorubicin (daunorubicinol; daunomycinol); structures are shown in Fig. 1. N-Acetyldaunorubicin is likewise reduced. A report of the findings of this aspect of our work follows.

\section{Materials and Methods}

Chemicals and Media. Daunorubicin-HCl was kindly supplied by Dr. JoHn D. Douros,

Address correspondence to: Dr. B. K. Hamilton. Chemotherapy Fermentation Laboratory, Frederick Cancer Research Center, P. O. Box B, Frederick, Maryland 21701, U.S.A.

* Research sponsored by the National Cancer Institute under Contract No. NOl-CO-25423 with Litton Bionetics, Inc. 
Fig. 1. Microbial transformation of daunorubicin to daunorubicinol

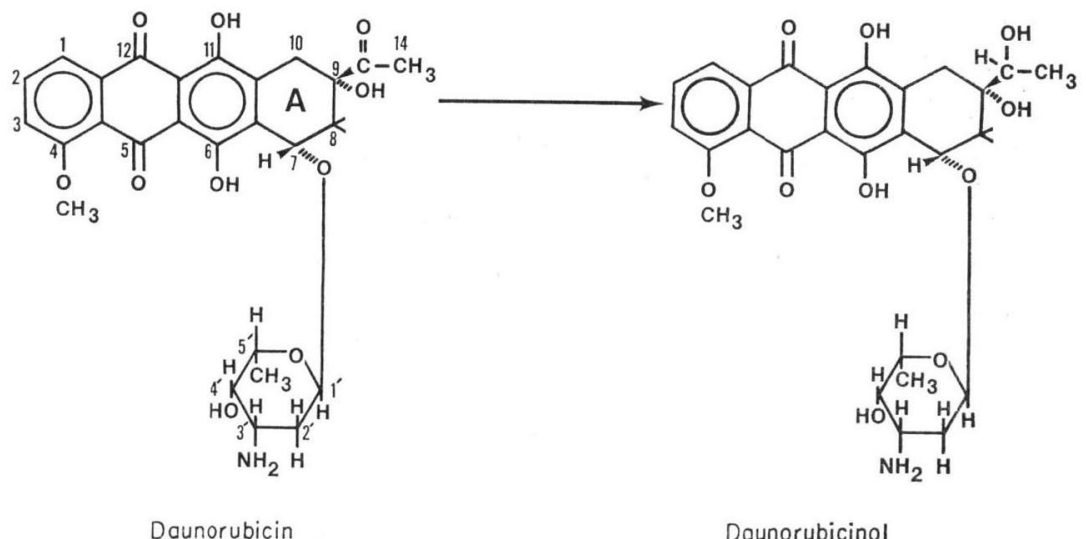

Division of Cancer Treatment, National Cancer Institute, U.S.A. N-Acetyldaunorubicin was chemically synthesized using procedures to be published. All other chemicals and media were standard commercially available grades.

Microorganisms. Unidentified actinomycete, yeast, and other bacterial and fungal cultures recently isolated from soils by our research section under Dr. A. L. GARretson were screened for ability to transform daunorubicin.

Biotransformation screen. Agitated $(250 \mathrm{rpm})$ baffled shake flasks $(50 \mathrm{ml})$ containing $10 \mathrm{ml}$ of medium were employed. Cultures were inoculated from streak plates using an inoculating loop or bayonet. Typically, an isolate was incubated at $28^{\circ} \mathrm{C}$ and/or $37^{\circ} \mathrm{C}$ for $1 \sim 3$ days in a medium which supported good growth (e.g., BBL trypticase-soy broth [pH 7.5] for bacteria and yeasts, inorganic salts-starch broth [pH 7.5] for actinomycetes, and CzAPEK-Dox broth enriched with trypticase-soy broth [pH 7.3] for molds). A filter-sterilized aqueous solution of daunorubicin- $\mathrm{HCl}$ was then added (final concentration in medium, $0.12 \mathrm{mg} / \mathrm{ml}$ ) and incubation was continued for $2 \sim 5$ days. One control consisted of daunorubicin- $\mathrm{HCl}$ added to uninoculated medium and incubated for the same period. A second control was comprised of an inoculated fermentation unsupplemented with daunorubicin- $\mathrm{HCl}$.

For biotransformation of $\mathrm{N}$-acetyldaunorubicin, the powdered anthracycline was dispersed in filter-sterilized absolute ethanol and charged to fermentation flasks $(0.25 \mathrm{ml}$ ethanol containing $1.25 \mathrm{mg} \mathrm{N}$-acetyldaunorubicin added to each 50 - $\mathrm{ml}$ flask containing $10 \mathrm{ml}$ broth).

Preparative biotransformation. Agitated $(250 \mathrm{rpm})$ baffled shake flasks (1 liter) containing $200 \mathrm{ml}$ of medium were used. Each flask was inoculated with a 1.0-ml aliquot of suspension from a slant washed with $5.0 \mathrm{ml}$ of $0.9 \%$ sterile saline.

Extraction and thin-layer chromatography. After incubation the whole broths were adjusted to $\mathrm{pH} 10.0$ with $2 \sim 4 \%$ aqueous sodium carbonate and were extracted with an aliquot of chloroform which had one-half the volume of the broth. In the case of the biotransformation screen, the chloroform extracts were directly spotted on silica gel plates $(0.25 \mathrm{~mm}$ in thickness) containing fluorescent indicator and the plates were developed by one-dimensional thin-layer chromatography (TLC) with two solvent systems ${ }^{2)}$ : IA, $\mathrm{CHCl}_{3}-\mathrm{MeOH}-\mathrm{H}_{2} \mathrm{O}(120: 20: 1)$; IB, $\mathrm{CHCl}_{3}-\mathrm{MeOH}-\mathrm{H}_{2} \mathrm{O}(80: 30: 3)$. The developed TLC plates were examined under visible and UV light for evidence of daunorubicin transformation products. For preparative isolations, the chloroform extracts were concentrated at $40^{\circ} \mathrm{C}$ under vacuum and chromatographed in the dark on silica gel preparative plates $(1.0 \mathrm{~mm}$ thick, no fluorescent indicator) with solvent system IA. The band containing transformation product was scraped off and suspended in solvent system IB for elution. The suspension was filtered with suction through paper, and the liquid eluate was washed in a separatory funnel with alkaline water (adjusted to $\mathrm{pH} 10$ with sodium 
carbonate). The resulting chloroform phase which remained after washing was vacuumevaporated to dryness to yield the final product.

Spectroscopy. IR spectra ( $\mathrm{KBr}$ pellet) were made with a Perkin Elmer 567 grating infrared spectrophotometer. UV-vis spectra (in methanol) were made with a Beckman model 25 instrument. Mass spectrometry was performed with a JEOL model JMS-01SG-2 double focusing mass spectrometer at an ionizing potential of $70 \mathrm{eV}$, trap current of $200 \mu \mathrm{A}$, and accelerating voltage of $10 \mathrm{KV}$. Peracetylated derivatives, prepared as described elsewhere ${ }^{3)}$, were introduced on a solid probe and spectra taken at $250 \sim 300^{\circ} \mathrm{C}$. ${ }^{1} \mathrm{H}-\mathrm{NMR}$ studies were made with a Varian XL-100 instrument with tetramethylsilane as the reference standard (spectral conditions are given with spectra of compound $\mathrm{A}$ : spectral conditions for peracetylated compound $\mathrm{A}$ are the same as for compound $\mathrm{A}$ in $\mathrm{CDCl}_{3}$ ). $\mathrm{CD}$ spectra (in methanol) were obtained on a Jasco J-40 instrument. The instrument was operated at $0.5 \mathrm{~m} / \mathrm{cm}$ sensitivity, four seconds-time constant, $1.0 \mathrm{~nm} / \mathrm{min}$ scan rate, $1.0 \mathrm{~nm}$ slit width, and a path length of $1.0 \mathrm{~cm}$. Sample concentrations were $0.003 \%$. ORD measurements (in $1.0 \mathrm{~mm} \mathrm{HCl}$ ) were done with a Jasco J-20 automatic recording spectropolarimeter. The ORD instrument was operated at a sensitivity of $5.0 \mathrm{~m} / \mathrm{cm}$, a chart speed of $1.0 \mathrm{~cm} / \mathrm{min}$, and a wave length expansion of $10 \mathrm{~nm} / \mathrm{cm}$. The cell path length was $1.0 \mathrm{~cm}$ and the temperature was $22^{\circ} \mathrm{C}$.

\section{Results}

Fermentation and Isolation of Daunorubicinol

When incubated in the presence of daunorubicin, many of the microbial isolates screened produced a product, designated compound A, which, in TLC, migrated with an Rf of 0.25 in solvent system IB, whereas daunorubicin itself displayed an $\mathrm{Rf}$ of 0.45 . In solvent system IA the $\mathrm{Rf}$ of compound $\mathrm{A}$ was 0.04 , whereas that of daunorubicin was 0.10 . Compound A did not appear in incubated but uninoculated flasks containing daunorubicin in fermentation broth nor did it appear in inoculated broths incubated in the absence of daunorubicin.

With one of the soil isolates, FCRC 151 (identified as Corynebacterium equi by the American Type Culture Collection), milligram quantities of compound A were produced for structural

Fig. 2. NMR spectrum of compound $\mathrm{A}$ in $\mathrm{CDCl}_{3}$

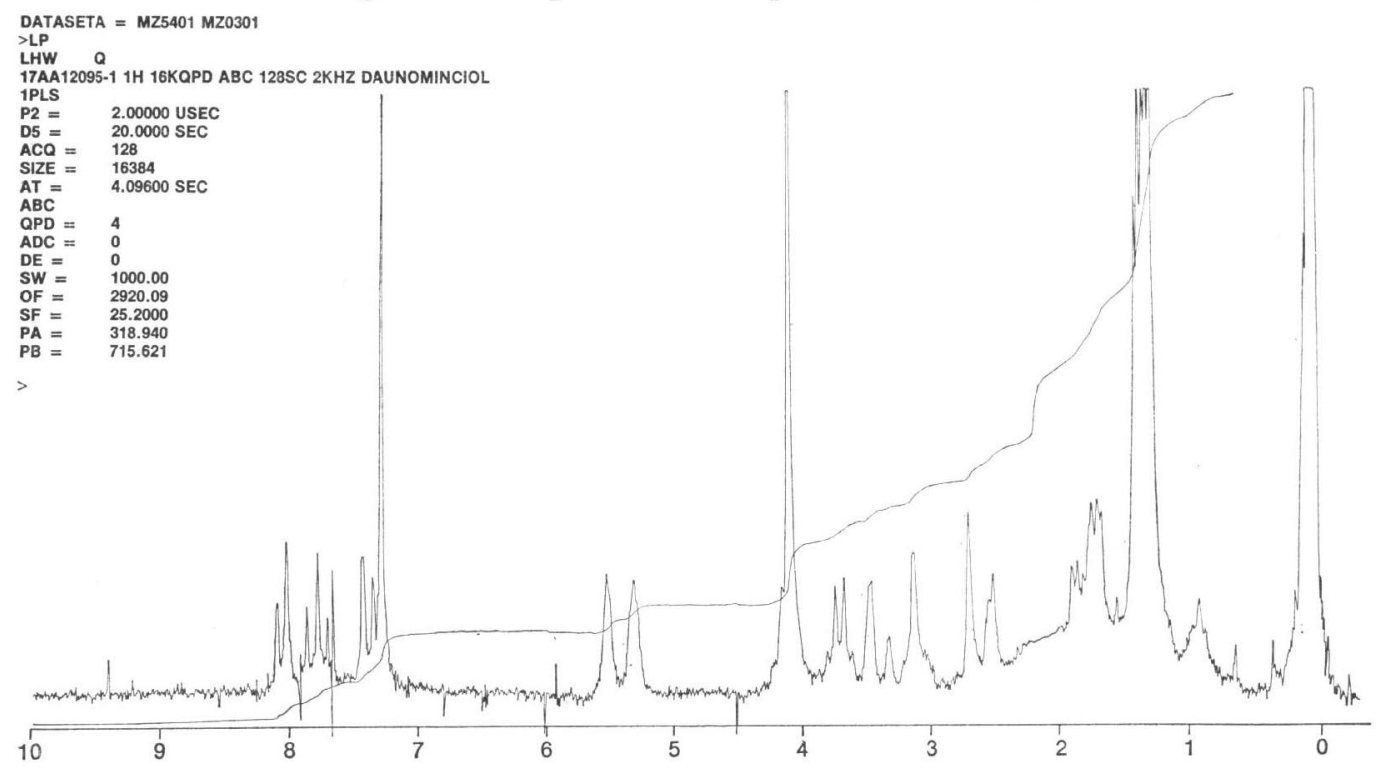


studies. FCRC 151 was grown in trypticase-soy broth at $37^{\circ} \mathrm{C}$. Twenty-four hours after inoculation, daunorubicin- $\mathrm{HCl}$ was added and incubation was continued for three more days. The final $\mathrm{pH}$ of the broth was 8.4 8.7. As determined by TLC, virtually no daunorubicin remained at the end of incubation. The product recovered by extraction and preparative thinlayer chromatography ran as one spot in TLC on cellulose with solvent systems IA and IB. This product, which proved to be daunorubicinol, was identified as described below.

\section{Identification of Daunorubicinol}

The TLC results already given indicated that compound $\mathrm{A}$ is more polar than daunorubicin. The IR spectrum indicated the absence of a carbonyl function at $1710 \mathrm{~cm}^{-1}$ which was attributed to the disappearance of the ketone function at C-134). Quantitative UV-vis spectroscopy suggested that the chromophore in compound $\mathrm{A}$ is the same as in daunorubicin ${ }^{5)}$ and that the molecular weight of compound $\mathrm{A}$ is very close to that of daunorubicin.

NMR studies of compound $A$ and its peracetylated derivatives were made with a $100 \mathrm{MHz}$ instrument using $\mathrm{D}_{5}$-pyridine and $\mathrm{CDCl}_{3}$ as solvents. The spectrum of compound $\mathrm{A}$ in $\mathrm{CDCl}_{3}$ is shown in Fig. 2. Significant differences in this spectrum as compared to the published results of ARCAMONe et al. ${ }^{8}$ ) on $\mathrm{N}$-acetyldaunorubicin (in $\mathrm{CDCl}_{3}$ as solvent) are as follows. Beside the obvious absence of the $\mathrm{N}$-acetyl at $\delta 1.93$ in the spectrum of compound $\mathrm{A}$, the threeproton singlet at $\delta 2.41$ present in the spectrum of $\mathrm{N}$-acetyldaunorubicin due to the side chain, $-\mathrm{CH}_{3}(\mathrm{C}-14$ in Fig. 1), cannot be observed. Instead, a doublet at $\delta 1.28$ (appears as quartet due to the $6^{\prime}-\mathrm{CH}_{3}$ at the same place; see spectrum in $\mathrm{D}_{5}$-pyridine for better resolution) is present. Also, a new quartet at $\delta 3.78$ is apparent, and irradiation at $\delta 3.78$ collapses the doublet at $\delta 1.28$. These results indicate that the side chain protons, $-\mathrm{CH}_{3}$, are coupled to a proton which is not present in $\mathrm{N}$-acetyldaunorubicin. No other major differences are evident between the spectra of compound $\mathrm{A}$ and $\mathrm{N}$-acetyldaunorubicin in chloroform. Chemical shifts, however, are slightly different and the $\mathrm{NH}_{2}$ protons could not be observed in our spectrum. The phenolic

Fig. 3. NMR spectrum of compound $\mathrm{A}$ in $\mathrm{D}_{5}$-pyridine

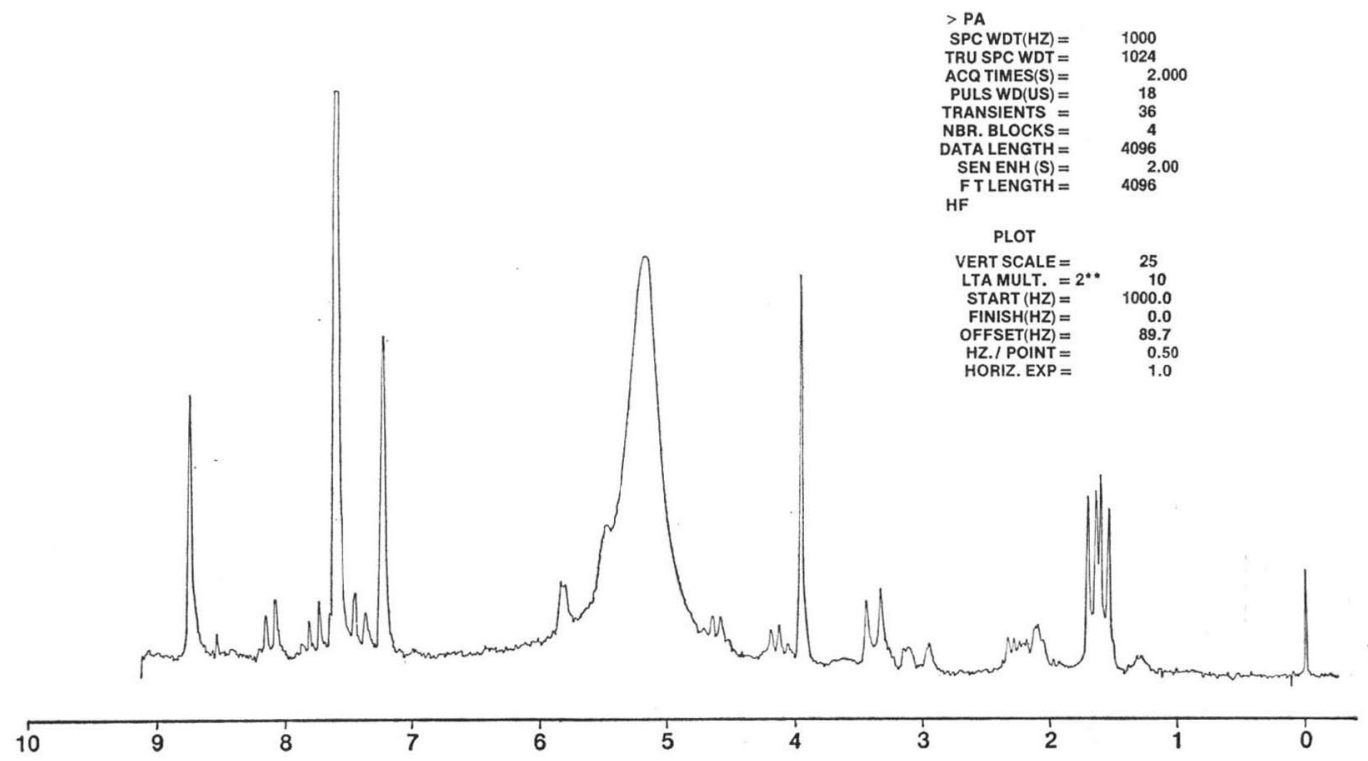


protons at $\delta 13.15$ and 13.85 were observed but are not shown in Fig. 2.

The $100 \mathrm{MHz}$ spectrum of compound $\mathrm{A}$ in $\mathrm{D}_{5}$-pyridine is shown in Fig. 3. As mentioned above, the side chain, $-\mathrm{CH}_{3}$, appears as a doublet at $\delta 1.62$ separate from the $6^{\prime}-\mathrm{CH}_{3}$. No additional gross characteristic information can be obtained from this spectrum. Shift assignments and coupling constants are shown in Table 1, and they are in agreement with those found for $\beta$-rhodomycinone by BrockMANN et al. ${ }^{7,8)}$

The $100 \mathrm{MHz}$ spectrum of peracetylated compound $\mathrm{A}$ in $\mathrm{CDCl}_{3}$ is shown in Fig. 4. Integration can account for 5 acetyl groups: the $\mathrm{N}$-acetyl at $\delta 1.93$ and the $-\mathrm{OH}$ acetyl at $\delta 2.13$,

Table 1. $100 \mathrm{MHz}$ Proton magnetic resonance spectrum of compound $\mathrm{A}$ in $\mathrm{D}_{5}$-Pyridine

\begin{tabular}{c|l|c|c}
\hline Protons & Chemical shift* & No. of $\mathrm{H}$ & Coupling constants \\
\hline 1 & $8.12(\mathrm{~d})$ & $1 \mathrm{H}$ & $\mathrm{J}_{1,2}=8 \mathrm{~Hz}$ \\
2 & $7.78(\mathrm{t})$ & $1 \mathrm{H}$ & $\mathrm{J}_{1,2}=\mathrm{J}_{2,3}=8 \mathrm{~Hz}$ \\
3 & 7.41 (d) & $1 \mathrm{H}$ & $\mathrm{J}_{2,3}=8 \mathrm{~Hz}$ \\
$1^{\prime}$ & $5.81(\mathrm{~d}, \mathrm{~d})$ & $1 \mathrm{H}$ & - \\
7 & $5.48(\mathrm{~d}, \mathrm{~d})$ & $1 \mathrm{H}$ & $\mathrm{J}_{7,8 \mathrm{eq}}=4 \mathrm{~Hz}, 2 \mathrm{~Hz}$ \\
8 & $3.04(\mathrm{br}, \mathrm{d}, \mathrm{d})$ & $2 \mathrm{H}$ & $\mathrm{J}_{8 \mathrm{~A}, 8 \mathrm{~B}}=16 \mathrm{~Hz}$ \\
10 & $3.38(\mathrm{~d})$ & $2 \mathrm{H}$ & $\mathrm{J}_{10 \mathrm{~A}, 10 \mathrm{~B}}=11 \mathrm{~Hz}$ \\
$2^{\prime}$ & $2.22(\mathrm{c})$ & $2 \mathrm{H}$ & - \\
$3^{\prime}$ & 2.12 & $1 \mathrm{H}$ & - \\
$4^{\prime}$ & - & - & - \\
$6^{\prime} \mathrm{CH}_{3}$ & $1.68(\mathrm{~d})$ & $3 \mathrm{H}$ & $\mathrm{J}_{\mathrm{CH}_{3}, \mathrm{H}_{5}}=6.5 \mathrm{~Hz}$ \\
$14 \mathrm{CH}_{3}$ & 1.57 (d) & $3 \mathrm{H}$ & $\mathrm{J}_{\mathrm{CH}_{3}, \mathrm{H}_{13}=6.5 \mathrm{~Hz}}$ \\
13 & $4.16(\mathrm{q})$ & $1 \mathrm{H}$ & $\mathrm{J}_{13, \mathrm{CH}_{3}}=6.5 \mathrm{~Hz}$ \\
$5^{\prime}$ & $4.62(\mathrm{q})$ & $1 \mathrm{H}$ & $\mathrm{J}_{\mathrm{CH}_{3}, \mathrm{H}_{5}}=6.5 \mathrm{~Hz}$ \\
$4 \mathrm{OCH}_{3}$ & $3.98(\mathrm{~s})$ & $3 \mathrm{H}$ & \\
\hline
\end{tabular}

* (d)-doublet, (t)-triplet, (d, d)-double doublet, (br, d, d)-broad double doublet, (c)-quintet, (q)-quartet, (s)-singlet.

Fig. 4. NMR spectrum of peracetylated compound $\mathrm{A}$ in $\mathrm{CDCl}_{3}$

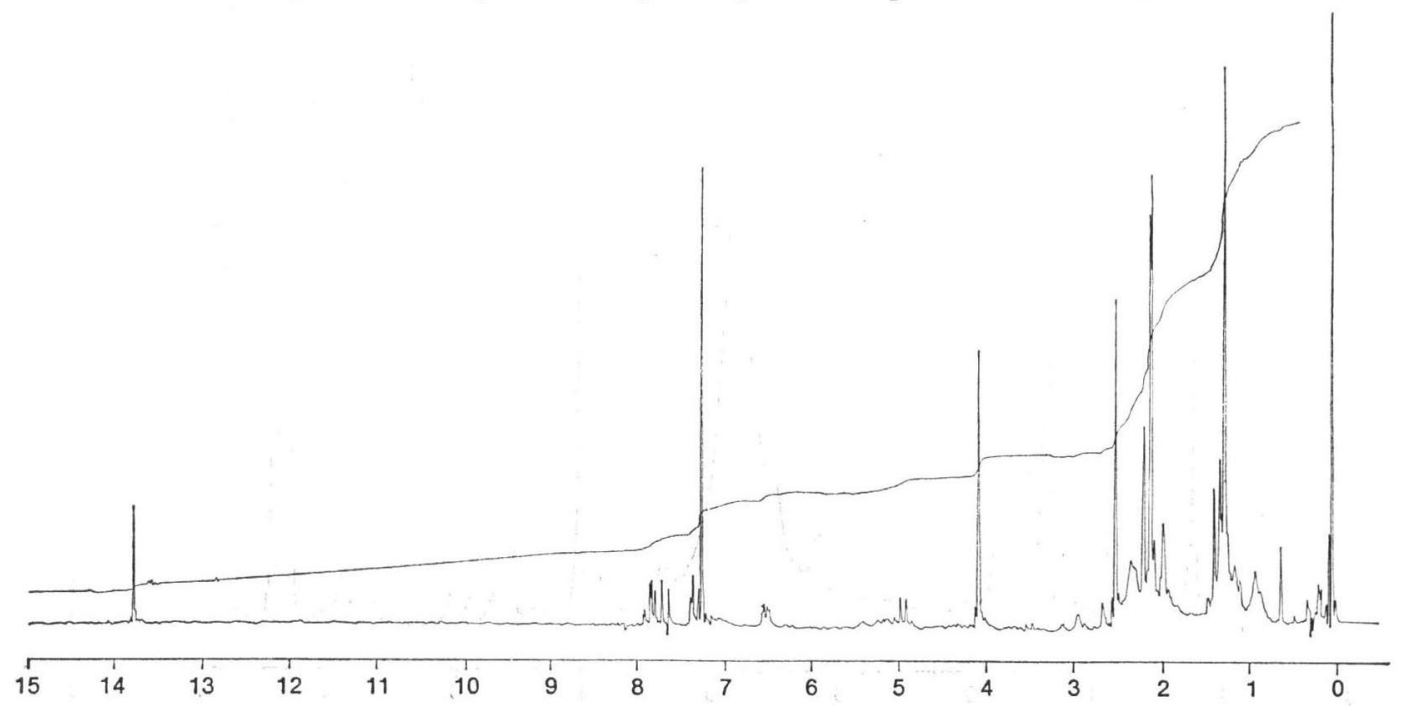


$2.19,2.20$ and 2.53. One phenolic - $\mathrm{OH}$ could not be acetylated in compound $\mathrm{A}$ as evidenced by the signal at $\delta 13.85^{\circ}$. Daunorubicin, the parent compound, can be acetylated at all $-\mathrm{OH}$ positions as found and described by Roller et al. ${ }^{3)}$ Apparently the change introduced by biotransformation, perhaps in combination with acetylation, prevented the acetylation of one phenolic $-\mathrm{OH}$ under the experimental conditions employed (steric hindrance, for example, might have blocked the $\mathrm{C}-11$ phenolic $\mathrm{OH}$ ).

The above NMR results, taken together with the TLC, UV-vis, and IR data, indicate that the only primary structural difference between daunorubicin and compound $\mathrm{A}$ is that the side chain ketone is reduced to an alcohol.

Further evidence for this proposed change comes from mass spectroscopic studies on the peracetylated derivative of compound A (see Fig. 5). As shown above by NMR studies on

Fig. 5. Mass spectrum of peracetylated derivative of compound A

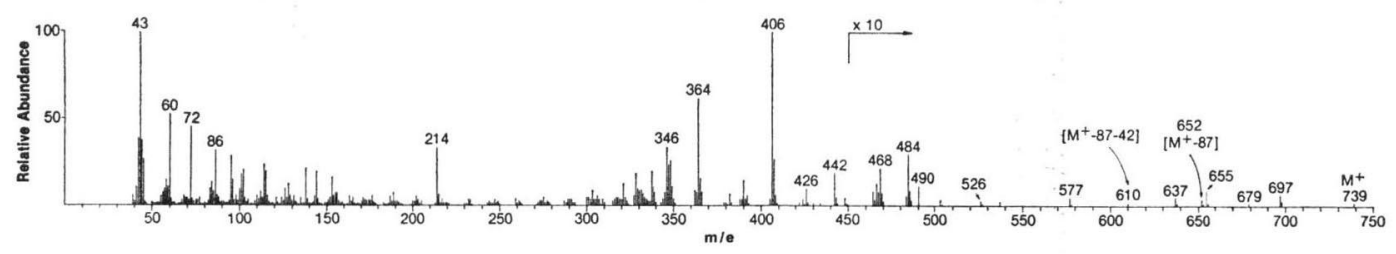

the peracetylated compound $\mathrm{A}$, one phenolic $-\mathrm{OH}$ was not acetylated. The expected $\mathrm{M}^{+}$is at $m / e 739$ and was observed in the mass spectrum. The fragmentation pattern of the peracetylated compound A was very similar to that of the peracetylated daunorubicin, which is described elsewhere $^{3)}$, and largely results from the loss of ketene and acetyl functions from the molecule, and from the aglycone and the sugar. In addition, a group of mass 87 split off in the spectrum of peracetylated compound $\mathbf{A}$, indicating that the side chain is the acetylated form of the reduced ketone function.

More evidence for the identity of compound A was obtained by comparison with daunorubicinol obtained from daunorubicin through reduction by human tissue as described by BACHUR $^{4)}$. Furthermore, it was of interest to determine whether the daunorubicinols produced by human tissue and by microorganism FCRC 151 have the same stereochemistry at the newly created asymmetric carbon. The two daunorubicinols were compared as follows: TLC in 3 solvent systems indicated identity ( $\mathrm{IA}, \mathrm{Rf}=0.04 ; \mathrm{IB}, \mathrm{Rf}=0.25$; $n$-propanol- $\mathrm{H}_{2} \mathrm{O}-\mathrm{MeOH}$-pyridine [8:2:1:1], $\mathrm{Rf}=0.87)$. The IR, $100 \mathrm{MHz}$ NMR $\left(\mathrm{CDCl}_{3}\right)$, UV-vis, and $\mathrm{CD}$ (see Fig. 6) spectra were superimposable. The optical rotation of each compound as a base was $[\alpha]_{D}^{20}=170^{\circ}$ ( $c$ 0.05 , EtOH-HCl). The ORD spectra showed a trough at $298 \mathrm{~nm}$ with equal intensity for both biologically produced daunorubicinols and were virtually identical between 500 and $240 \mathrm{~nm}$, indicating the same stereochemistry in both compounds. The absolute configuration of the newly created asymmetric carbon remains to be determined.

The $100 \mathrm{MHz}$ NMR spectrum of compound $\mathbf{A}$ in $\mathrm{D}_{5}$-pyridine (Table 1 ) also supplied information on the conformation of the $A$ ring (see Fig. 1) in the aglycone portion of the molecule. The similarity of the conformations of the $A$ rings in daunomycinone and $\beta$-rhodomycinone was deduced by BROCKMANN et al. ${ }^{7,8)}$ based in part on NMR spectra. Comparison of data in Table 1 with data given by BrockmanN et al. indicated that the $A$ ring in compound 
Fig. 6. CD spectra of compound $\mathrm{A}$ and daunorubicinol produced from daunorubicin by human tissue

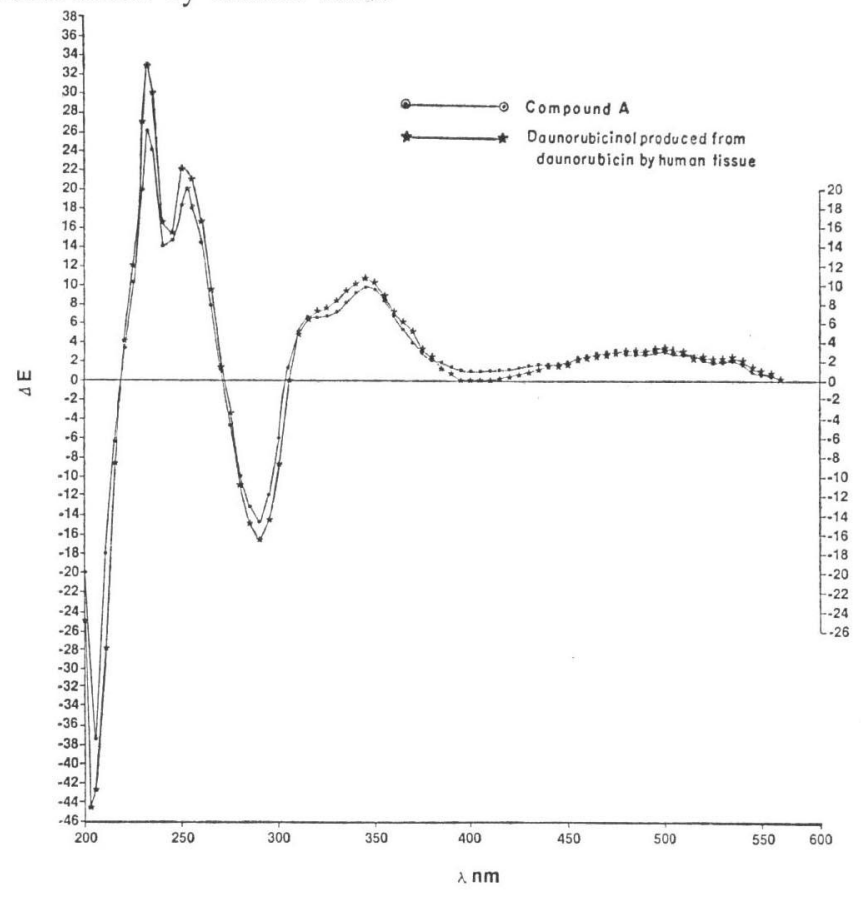

A has the same conformation as the $A$ ring in daunomycinone and $\beta$-rhodomycinone, that is, half chair and $7 \mathrm{H}$ equatorial. In particular, in the spectrum of compound $\mathrm{A}$, the $7 \mathrm{H}$ proton, $\delta 5.48$ (double doublet, $\mathrm{J}=4 \mathrm{~Hz}, 2 \mathrm{~Hz}$ ), is split due to equatorial coupling to $8 \mathrm{H}$. This finding compares well to that of BROCKMANN and NIEMEYER ${ }^{7)}$ for $\beta$-rhodomycinone in $\mathrm{D}_{5}$-pyridine (7H: $\delta 5.55, \mathrm{~J}=4 \mathrm{~Hz}, 2 \mathrm{~Hz}$ ). In addition, in the spectrum for compound $\mathrm{A}$, both $8 \mathrm{H}$ protons (A: $\delta 3.12, \mathrm{~J}_{7-8}=4 \mathrm{~Hz} ; \mathrm{B}: \delta 2.96, \mathrm{~J}_{7-8}=2 \mathrm{~Hz} ; \mathrm{J}_{8 \mathrm{e}-8 \mathrm{a}}=16 \mathrm{~Hz}$ ) are split into double doublets due to ABX coupling. This finding also compares well to that of BRockmann and Niemeyer (A: $\left.\delta 2.55, \mathrm{~J}_{7-8}=4 \mathrm{~Hz} ; \mathrm{B}: \delta 2.44, \mathrm{~J}_{7-8}=2 \mathrm{~Hz} ; \mathrm{J}_{8 \mathrm{e}-8 \mathrm{a}}=14 \mathrm{~Hz}\right)$. Moreover, the 10H's which appeared at $\delta 3.33$ and $\delta 3.44(\mathrm{~J}=11 \mathrm{~Hz})$ were not split due to long range coupling to $8 \mathrm{H}$ in compound A and $\beta$-rhodomycinone in $\mathrm{D}_{5}$-pyridine, while such splitting was found by ARCAmone et al. ${ }^{\text {s) }}$

\section{N-Acetyldaunorubicinol}

FCRC 151 was grown by applying the procedure employed for daunorubicin biotransformation, and $\mathrm{N}$-acetyldaunorubicin was added 24 hours after inoculation. Incubation was continued for three more days. The final $\mathrm{pH}$ of the broth was 8.4. In TLC, the Rf's of Nacetyldaunorubicin extracted into chloroform from uninoculated broth were 0.58 with solvent system IA and 0.82 with solvent system IB. TLC of the chloroform extract from inoculated broth yielded a product with Rf's of 0.44 with solvent system IA and 0.73 with solvent system IB; only transformation product appeared, and no $\mathrm{N}$-acetyldaunorubicin remained. Identity of the transformation product as $\mathrm{N}$-acetyldaunorubicinol was secured by IR spectroscopy (absence of the carbonyl function at $1710 \mathrm{~cm}^{-1}$ ) and $\mathrm{NMR}$ spectroscopy in $\mathrm{CDCl}_{3}$ (spectrum of $\mathrm{N}$ acetyldaunorubicinol has the characteristic $\mathrm{N}$-acetyl signal at $\delta 1.93$ for 3 protons, but otherwise is identical to that of daunorubicinol). Elemental analysis indicated the presence of $2.45 \% \mathrm{~N}$ 
(theoretical $2.46 \%$ ).

\section{Discussion}

Microbial reduction of daunorubicin to daunorubicinol has also been observed by other workers $^{9)}$ who found that the transformation can be carried out by Streptomyces lavendulae ATCC 8644, S. roseochromogenes ATCC 13400, Corynebacterium simplex ATCC 6946, and Bacterium cyclooxydans ATCC 12673. In addition, daunorubicinol can be prepared by direct fermentation ${ }^{10,11)}$ or by chemical reduction of daunorubicin ${ }^{12)}$. BACHUR ${ }^{13)}$ has reported that daunorubicinol is a major metabolite of daunorubicin appearing in rats and humans, and DIMARCO and ARCAMONE ${ }^{14)}$ observed that daunorubicinol is a metabolite of the daunorubicin producing strain of Streptomyces peucetius. These observations which indicate that mammals and microorganisms reduce daunorubicin to daunorubicinol reinforce the concepts recently reviewed by SMITH and $\operatorname{RoSAZZ}_{\left.\Lambda^{15}\right)}$ on the parallelism between mammalian and microbial metabolism of drugs.

The antitumor activity of daunorubicinol has been studied ${ }^{10,16,17)}$. N-Acetyldaunorubicinol is to our knowledge a new compound which is yet to be tested for antitumor activity.

\section{Acknowledgements}

We thank Dr. John D. Douros of the Division of Cancer Treatment, National Cancer Institute, USA, for supplying daunorubicin and for stimulating discussions. We are also indebted to Ms. DANA WARNICK of our laboratories for maintenance and supply of cultures.

\section{References}

1) Wiley, P. F. \& V.P. Marshall: Microbial conversion of anthracycline antibiotics. J. Antibiotics 28: 838 840,1975

2) Yamamoto, J.; E. M. Acton \& D. W. Henry: Antitumor activity of some derivatives of daunorubicin at the amino and methyl ketone functions. J. Med. Chem. 15: 872 875, 1972

3) Roller, P. O.; M. Sutphin \& A. A. Aszalos: Mass spectrometry of N-acetylated daunorubicin derivatives. Biomed. Mass Spectrom 3: 166 171, 1976

4) BACHUR, N. R.: Daunorubicinol, a major metabolite of daunorubicin: Isolation from human urine and enzymatic reactions. J. Pharmacol. Exp. Ther. 177: 573 578, 1971

5) British Patent 1,003,383: Antibiotic F. I. 1762 (Daunomycin). September 2, 1965

6) Arcamone, R.; G. Cassinelli, G. Francheschi \& P. Orezzi: The total absolute configuration of daunomycin. Tetrahedron Letters 1968-30: 3353 3356, 1968

7) BrockmanN, H. \& J. Niemeyer: Konfiguration and Konformation von $\alpha$-Rhodomycinon, $\beta$ Rhodomycinon und $\beta$-iso-Rhodomycinon. Chem. Ber. 100: 3578 3587, 1967

8) Brockmann, H.; H. Brockmann, Jr. \& J. Niemeyer: Die absolute Konfiguration der Anthracyclinone. Tetrahedron Letters 1968-45: 4719 4724, 1968

9) Florent, J.; J. Lunel \& J. Renaut: Neue Vorfahren zur Herstellung des Antibiotikums 20,789 R. P. German Patent 2,456,139. May 28, 1975

10) Arcamone, F.; G. Cassinelli, S. Penco \& L. Tognoli: Dihydrodaunomycin antibiotic and derivative thereof. U.S. Patent 3,686,163. August 22, 1972

11) Lunel, J. \& J. Preud' homme: Nouvel antibiotique et sa préparation par culture d'un streptomyces. French Patent 1,583,752. October 27, 1969

12) British Patent 1,322,872: Process for the preparation of antibiotics 20,798 RP and 27,706 RP and the antibiotic 27,706 RP. July 11, 1973

13) BACHUR, N. R.: Adriamycin-daunorubicin cellular pharmacodynamics. Biochemical Pharmacology Supplement Number 2: 207 216, 1974

14) DiMARCo, A. \& F. ARCAMONE: DNA complexing antibiotics: daunomycin, adriamycin and their derivatives. Arzneim.-Forsch. 25: 368 375, 1975

15) Sмith, R. V. \& J. P. Rosazza: Microbial models of mammalian metabolism. J. Pharmaceut. Sci. $64: 1737 \sim 1759,1975$ 
16) Chandra, P.; D. Gericke \& F. Zunioko: The relationship of chemical structure to cytostatic activity of some daunomycin derivatives. Pharmacol. Res. Commun. 4: 269 272, 1972

17) diMarco, A.; A. M. Casazza, T. Dasdia, F. Giuliani, L. Lenaz \& C. Soranzo: Cytotoxic, antiviral, and antitumor activity of some derivatives of daunomycin (NSC-82151). Cancer Chemoth. Rep. Part 1 57: 269 274, 1973 